\title{
Preclinical evidence of multiple mechanisms underlying trastuzumab resistance in gastric cancer
}

\author{
Chiara Arienti ${ }^{1}$, Michele Zanoni ${ }^{1}$, Sara Pignatta ${ }^{1}$, Alberto Del Rio $^{2,3}{ }^{\text {, Silvia Carloni }}{ }^{1}$, \\ Michela Tebaldi ${ }^{1}$, Gianluca Tedaldi ${ }^{1}$, Anna Tesei ${ }^{1}$ \\ ${ }^{1}$ Biosciences Laboratory, Istituto Scientifico Romagnolo per lo Studio e la Cura dei Tumori (IRST) IRCCS, Meldola, Italy \\ ${ }^{2}$ Institute of Organic Synthesis and Photoreactivity (ISOF), National Research Council (CNR), Bologna, Italy \\ ${ }^{3}$ Innovamol Srls, Modena, Italy \\ Correspondence to: Chiara Arienti, e-mail: chiara.arienti@irst.emr.it \\ Anna Tesei, e-mail: anna.tesei@irst.emr.it
}

Keywords: trastuzumab resistance, gastric cancer, HER family receptors, HER signaling pathways, IQGAPI

Received: October 19, $2015 \quad$ Accepted: February 11, 2016

Published: February 22, 2016

\section{ABSTRACT}

HER2-positive advanced gastric cancer patients frequently develop resistance to trastuzumab through mechanisms still poorly understood. In breast cancer, other members of the HER-family are known to be involved in trastuzumab-resistance, as is overexpression of the scaffold protein IQGAP1. In the present work, we investigated acquired resistance to trastuzumab in gastric cancer experimental models. Trastuzumab-resistant (HR) subclones derived from 3 HER2-overexpressing gastric cancer cells were generated and characterized for alterations in HER2- signaling mechanisms by next-generation sequencing, immunohistochemical, western blot and qRT-PCR techniques, and molecular modeling analysis. All subclones showed a reduced growth rate with respect to parental cell lines but each had a different resistance mechanism. In NCI N87 HR cells, characterized by a marked increase in HER2-signaling pathways with respect to the parental cell line, trastuzumab sensitivity was restored when IQGAP1 expression was silenced. AKG HR subclone showed higher HER3 protein expression than the parental line. High nuclear HER4 levels were observed in KKP HR cells. In conclusion, our study revealed that high IQGAP1 expression leads to resistance to trastuzumab in gastric cancer. Furthermore, 2 new mutations of the HER2 gene that may be involved in acquired resistance were identified in AKG HR and KKP HR subclones.

\section{INTRODUCTION}

Gastric cancer is the fourth most common malignant disease and the second leading cause of cancer-related death worldwide [1]. In Europe, it is the fifth most common cancer among men and women, representing about $23 \%$ of all cancers. Depending on tumor characteristics and stage [2], treatment modalities include a combination of surgery, chemotherapy generally based upon a platinum-fluoropyrimidine doublet, and radiation therapy $[3,4]$. Although fluorouracil (5-FU)based regimens have proven feasible and effective in the treatment of solid tumors, their therapeutic effect is unsatisfactory in advanced gastric cancer, i.e., 7-51\% overall response rate and 6 to $12-$ month median survival [5-7]. Thus, various combination regimens have been developed.

Trastuzumab, a monoclonal antibody targeting human epidermal growth factor receptor 2 (HER2), induces antibody-dependent cellular cytotoxicity and inhibits HER2-mediated signaling by binding the extracellular domain of HER2. Amplification of the HER2 gene is observed in $20 \%-30 \%$ of gastric and gastroesophageal junction cancer [8-12] and is indicative of a poor prognosis, as recently highlighted in the systematic meta-analysis by Jorgensen et al. [13]. In 2010, the phase III ToGA trial showed the superiority of trastuzumab plus chemotherapy (based on a cisplatin- 
fluoropyrimidine doublet) in patients with HER2-positive metastatic gastric cancer over chemotherapy alone in terms of response rate, progression-free survival (PFS) and overall survival (OS) [14]. These results led to the approval of trastuzumab as the first molecular targeted therapy for gastric cancer. However, subsequent clinical trials (TYTAN8 and LOGiC9) failed to show a survival advantage with the use of another anti-HER2 treatment, lapatinib [15]. Overall, the efficacy of HER2-targeted agents has proven more limited and unsatisfactory than originally expected because the majority of patients with gastric cancer develop acquire resistance to treatment [16]. In particular, it has been observed that, whilst few patients with HER2-positive advanced gastric cancer exhibit primary resistance to trastuzumab, all acquire resistance after a relatively short period of time (median PFS 6.7 months) [17], as already observed in HER2-positive breast cancer patients. The identification of mechanisms underlying treatment resistance would thus enhance the benefit from HER2-targeted therapy in patients with HER2-positive gastric cancer.

The etiology of resistance to HER2-directed therapies has been widely investigated in breast cancer [18-22]. Several molecular mechanisms underlying acquired resistance to HER-2 inhibitors have been described, including the activation of c-Src tyrosine kinase [20], HER3 upregulation [23], activating mutations in the p110a subunit of PI3K (PIK3CA) [24], and enhanced HER-ligand autocrine signaling [25]. It has also been proven that resistance to HER2-targeted therapy can trigger genetic alterations of receptor tyrosine kinases (RTKs), leading to the activation of downstream signaling targets and alternative pathways to compensate for HER2 inhibition [26, 27]. Numerous studies have concluded that induction of the HER3 pathway is one of the reasons underlying this type of resistance [28-30]. Moreover, Mohd Nafi et al. observed that HER4 activation, cleavage and nuclear translocation influence sensitivity and resistance to trastuzumab in HER2-positive breast cancer [31].

A recent study reported that IQGAP1, a scaffold protein of $189-\mathrm{kDa}$ ubiquitously expressed in all human tissues, governs HER2 expression, phosphorylation and signaling in breast cancer cell lines [32]. Moreover, IQGAP1 protein is overexpressed in squamous cell [33] and hepatocellular [34] carcinoma, astrocytoma [35], and aggressive forms of gastric cancer [36]. In particular, White et al. [37] showed that IQGAPloverexpression is correlated with trastuzumab-induced resistance in breast cancer cell lines. However, its involvement in resistance to trastuzumab in gastric cancer has never been investigated. In the present work we investigated mechanisms of resistance induced by trastuzumab in in vitro experimental gastric cancer cell lines rendered resistant to the antiproliferative effect of the drug.

\section{RESULTS}

\section{Baseline expression and mutational status of HER2, -3 and -4 receptors in a panel of established human gastric cancer cell lines}

Positivity to HER2, -3 and -4 proteins and their cellular localization in the human gastric cell lines NCI N87, AKG and KKP was assessed by immunohistochemistry (Figure 1A). HER2, -3 and -4 receptors were highly expressed in all 3 cell lines, albeit with a different diffusion pattern. In particular, HER2 was highly expressed in NCI N87 with a diffuse plasma membrane and cytosolic staining pattern. HER3 was also highly expressed in NCI N87 cells ( $\sim 95 \%$ of positive cells) in both the plasma membrane and cytosol. In addition, HER3 was expressed in KKP and AKG cells, albeit to a lesser degree ( $\sim 40 \%$ and $\sim 30 \%$ of positive cells, respectively), whereas its staining pattern was mainly restricted to the cytosol. Finally, HER4 protein was mainly localized in the nuclei and cytoplasm of AKG cells.

We used next generation sequencing (NGS) to search for genomic alterations that might predispose to a different response to treatment with trastuzumab (average depth of 2779.73 and $99.7 \%$ of targets with a minimum coverage of 50). We first investigated whether the different cell lines harbored genetic alterations of HER2, HER 3 or HER4 genes and which, if any, were common to AKG, KKP and NCI N87 (Figure 1B). All 3 cell lines showed several alterations in the gene sequences investigated, only 12 of which are not annotated in the dbSNP and COSMIC databases. In particular, 4 of these were exonic variants (Tables 1 and 2). Notably, only 5 gene variants were common to all 3 lines, i.e. HER3 variants c.-211delCT and c. C2270A; and HER4 variants IVS17-60delAG, IVS17-102insG and IVS7-7delT (Figure 1B and Table 1).

A pairwise comparison of the 3 cell lines revealed that AKG and KKP cell lines shared the highest number of gene alterations, one in HER2, 2 in HER 3 and one in HER4 (Table 1). Conversely, NCI N87 showed the highest number of genetic variants (13) relating to all 3 HER receptors (5 variants in HER2, 3 in HER3 and 5 in HER4) that were not found in AKG or KKP (Table 2).

\section{Generation of trastuzumab-resistant subclones}

All of the cell lines were sensitive to trastuzumab, as confirmed by the clonogenic assay in which $\mathrm{IC}_{50}$ values were lower than the peak plasma concentration of the drug (Figure 2A). In particular, NCI N87, the cell line harboring the highest number of HER2 variants, was the most sensitive to the cytotoxic action of trastuzumab $\left(\mathrm{IC}_{50}\right.$ value of $7 \mu \mathrm{g} / \mathrm{ml}$ ), whereas the AKG cells (3 gene variants) were the most resistant $\left(\mathrm{IC}_{50}=40 \mu \mathrm{g} / \mathrm{ml}\right)$. The 
incorporation of BrdU after a 72-h treatment with the drug confirmed these data. In fact, after treatment with $100 \mu \mathrm{g} / \mathrm{ml}$ of trastuzumab, NCI N87 showed a lower incorporation of BrdU than that of untreated cells $(35 \%$ and $42 \%$, respectively), while no substantial change in cell proliferation was seen in AKG (Figure 2B).

We generated trastuzumab-resistant (HR) subclones derived from the above gastric cancer cell lines to investigate the mechanisms underlying acquired resistance to trastuzumab. Starting from the peak plasma concentration of $100 \mu \mathrm{g} / \mathrm{ml}$, all cell lines were exposed to gradually increasing concentrations of trastuzumab for a period of 8-12 months. We thus obtained trastuzumabresistant subclones that were capable of growing in culture medium containing a drug concentration of $250 \mu \mathrm{g} / \mathrm{ml}$ for the NCI N87 HR subclone and $400 \mu \mathrm{g} / \mathrm{ml}$ for the AKG HR and KKP HR subclones (Figure 2C).

The resistant phenotype was stable and all subclones showed $\mathrm{IC}_{50}$ values higher than the peak plasma concentration of the drug ranging from $120 \mu \mathrm{g} / \mathrm{ml}$ (AKG $\mathrm{HR}$ ) to $200 \mu \mathrm{g} / \mathrm{ml}$ (KKP HR and NCI N87 HR) (Figure $2 \mathrm{C})$. We also evaluated the relative resistance $\mathrm{IC}_{50}$ index $\left(\mathrm{RR} \mathrm{IC}_{50}\right.$ ) of each subclone obtained (Figure 2D). Notably, the data revealed that the subclone with the highest RR $\mathrm{IC}_{50}$ value, NCI N87 HR, was obtained from the cell line with the highest number of genetic variants. In addition, trastuzumab was found to stimulate proliferation in all subclones, significantly so for NCI N87 HR cells $(\mathrm{p}<0.05)$ (Figure 2E).
We also observed changes in doubling times that were cell line-dependent (Figure 2F), e.g. AKG HR cells grew more rapidly, albeit not significantly, than those of the parental line. KKP and its subclone KKP HR showed similar growth, while NCI N87 HR grew significantly slower than its parental line $(\mathrm{p}<0.05)$.

The resistant subclone of NCI N87 displayed a different cell distribution in cell cycle phases compared to parental cells. In particular, an increase of cells in G0/G1 phase was observed in NCI-N87 HR (84.0\%) compared to NCI N87 cells (69.63\%), whereas a lower percentage of S-phase cells was found in the HR subclone than in the parental line (11.02\% NCI N87 HR vs. $24.17 \%$ NCI N87) (Figure 2G).

\section{Different HER2 signaling modulation in HR subclones}

We quantified HER2 expression levels by flow cytometry and western blot analysis to verify whether its expression was modified in HR subclones (Figure 3). Flow cytometric analysis revealed an increase in HER2 membrane levels in NCI N87 HR cells with respect to parental cells (Figure 3A). Furthermore, immunohistochemistry analysis showed that HER2 was highly expressed in NCI N87 HR cells ( $\sim 95 \%$ positive cells) which had both membrane and a cytoplasmic positivity (Figure 3B). We also detected a marked increase in p-HER2, AKT, p-AKT and MAPK protein

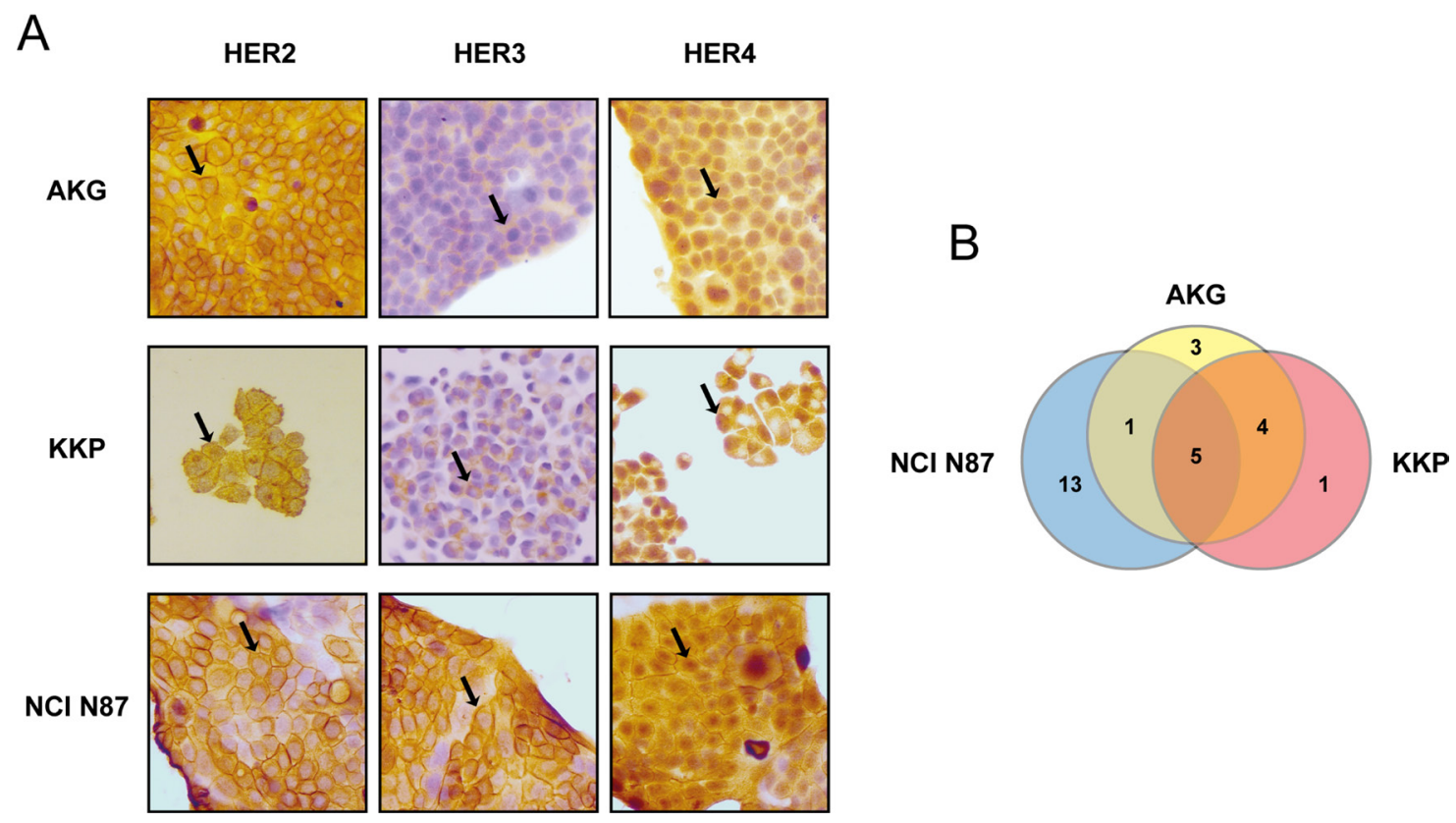

Figure 1: Baseline expression and mutational status of HER2, -3 and -4 receptors in a panel of established human gastric cancer cell lines. A. HER2, HER3 and HER4 staining by IHC in gastric cancer cell lines AKG, KKP and NCI N87. Sample reactivity was evaluated by light microscopy $(\times 200$ magnification) by two independent observers. Marker positivity was evaluated in a semiquantitative manner, as described in the Materials and Methods section. B. Venn-diagram comparison of gene variants across the three cell lines. The numbers refer to the number of somatic mutations affecting HER2, -3 and -4 . 
Table 1: Genetic variants shared in parental gastric cancer cell lines

\begin{tabular}{|c|c|c|c|c|c|c|c|}
\hline Cell lines & gene & variant & localization & variant effect & $\begin{array}{l}\text { protein } \\
\text { change }\end{array}$ & annotation & $\begin{array}{c}\text { Functional } \\
\text { prediction score } \\
\text { (HVAR, SIFT, } \\
\text { MutationAssessor) }\end{array}$ \\
\hline \multirow[t]{4}{*}{ AKG KKP } & HER2 & c.C3508G & exonic & $\begin{array}{c}\text { nonsynonymous } \\
\text { SNV }\end{array}$ & p.P1170A & rs1058808 & $\mathrm{P}, \mathrm{D}, \mathrm{M}$ \\
\hline & HER3 & c. $-277 \mathrm{~T}>\mathrm{C}$ & upstream & - & - & rs7297175 & - \\
\hline & & $\mathrm{IVS} 2+8 \mathrm{~A}>\mathrm{T}$ & intronic & - & - & rs2271194 & - \\
\hline & HER4 & IVS16-23insA & intronic & - & - & rs202070359 & - \\
\hline AKG NCIN87 & HER4 & IVS12-15T >C & intronic & - & - & rs4673628 & - \\
\hline \multirow[t]{5}{*}{$\begin{array}{l}\text { AKG KKP } \\
\text { NCIN87 }\end{array}$} & HER3 & c.-211delCT & UTR5 & - & - & - & - \\
\hline & & c.C2270A & $\begin{array}{l}\text { exonic; } \\
\text { splicing }\end{array}$ & $\begin{array}{c}\text { nonsynonymous } \\
\text { SNV }\end{array}$ & p.T757K & - & $\mathrm{D}, \mathrm{D}, \mathrm{N}$ \\
\hline & HER4 & IVS17-60delAG & intronic & - & - & rs146953835 & - \\
\hline & & IVS17-102insG & intronic & - & - & rs76332141 & - \\
\hline & & IVS7-7delT & intronic & - & - & rs67894136 & - \\
\hline
\end{tabular}

HVAR outputs: P, potentially deleterious; D, probably deleterious; SIFT outputs: D, deleterious; MutationAssessor outputs:, $\mathrm{N}$, neutral; $\mathrm{M}$, medium; - , unknown

levels in NCI N87 HR with respect to NCI N87 (Figure 3C). Protein levels of p-HER2 and of molecules involved in HER2 signaling were also analyzed by Western blot in the other cell lines. An increase in AKT expression was detected in KKP HR cells, while MAPK and p27 expression levels were significantly lower than those of the parental cell line. In AKG HR cell line, we observed an increase in mTOR and MAPK protein expression and a sharp decrease in AKT protein expression with respect to parental AKG cells.

\section{Knockdown of IQGAP1 inhibits HER2- stimulated NCI-N87 HR cell growth}

IQGAP1 gene and protein expression were analyzed in all cell lines to verify their involvement in trastuzumabrelated resistance (Figure 4). A different modulation of the protein was observed in the 3 parental cell lines, AKG cells showing the highest IQGAP1 expression and KKP the lowest (Figure 4A). This expression pattern was confirmed by gene expression analysis (data not shown). We also observed an increase in IQGAP1 protein expression of HR-resistant subclones with respect to parental cells $(\mathrm{p}<0.05)$. However, trastuzumab-resistant NCI N87 cells were the only subclones to show an increase in IQGAP1 gene expression levels with respect to parental cells (expression value 2.5-fold higher than that of NCI N87).

The influence of IQGAP1 on trastuzumab resistance was evaluated by transfecting siRNAs against IQGAP1 into NCI N87 HR cells, the subclone with the highest drug resistance phenotype (also confirmed by its RR value). Gene silencing induced a total block in protein synthesis and a dramatic decrease (up to $90 \%$ ) in mRNA expression (Figure 4B). IQGAP1-silenced NCI N87 HR cells exposed to different concentrations of trastuzumab for $144 \mathrm{~h}$ regained a certain degree of sensitivity to trastuzumab, reaching an $\mathrm{IC}_{50}$ value of $110 \mu \mathrm{g} / \mathrm{ml}$. Furthermore, the RR decreased from 28.57 to 15.71 , indicating an increase in sensitivity to trastuzumab (Figure 4C). These data were further supported by the results from a colony formation assay showing a reduction of about $55 \%$ in the number of colonies when IQGAP1-silenced NCI N87 HR cells were exposed to trastuzumab $100 \mu \mathrm{g} / \mathrm{ml}$ for 14 days.

\section{Analysis of HER3 and HER4 protein expression in HR subclones}

HER3 and HER4 expression levels in the plasma membrane were quantified by western blot analysis and immunohistochemistry to evaluate their role in the acquired resistance to trastuzumab (Figure 5). Protein expression detected by western blot revealed increased HER3 and decreased HER4 protein levels in AKG HR cells compared to parental cells. KKP HR subclone showed higher levels of HER4 than KKP cells. Finally, NCI N87 HR only showed significantly lower HER4 expression than parental cells (Figure 5A). HER3 was also highly expressed in about $95 \%$ of AKG HR cells, with cytoplasmic positivity. Furthermore, 
Table 2: Genetic variants not shared by parental gastric cancer cell lines

\begin{tabular}{|c|c|c|c|c|c|c|c|}
\hline Cell lines & gene & variant & localization & variant effect & $\begin{array}{l}\text { protein } \\
\text { change }\end{array}$ & annotation & $\begin{array}{c}\text { Funtional } \\
\text { prediction score } \\
\text { (HVAR, SIFT, } \\
\text { MutationAssessor) }\end{array}$ \\
\hline \multirow[t]{3}{*}{ AKG } & HER2 & IVS8-7T $>C$ & intronic (7bp) & - & - & - & - \\
\hline & & c.T3182C & exonic & $\begin{array}{c}\text { nonsynonymous } \\
\text { SNV }\end{array}$ & p.L1061P & rs 141142822 & $\mathrm{P}, \mathrm{T}, \mathrm{N}$ \\
\hline & HER3 & c.-195delCA & UTR5 & - & - & - & - \\
\hline KKP & HER2 & c.T2709G & exonic & $\begin{array}{c}\text { nonsynonymous } \\
\text { SNV }\end{array}$ & p.S903R & - & $\mathrm{D}, \mathrm{D}, \mathrm{H}$ \\
\hline \multirow[t]{13}{*}{ NCIN87 } & HER2 & c.A2698C & exonic & $\begin{array}{c}\text { nonsynonymous } \\
\text { SNV }\end{array}$ & p.T900P & - & $\mathrm{D}, \mathrm{D}, \mathrm{M}$ \\
\hline & & c.C2692G & exonic & $\begin{array}{c}\text { nonsynonymous } \\
\text { SNV }\end{array}$ & p.R898G & - & $\mathrm{D}, \mathrm{D}, \mathrm{L}$ \\
\hline & & c.C2704A & exonic & $\begin{array}{c}\text { nonsynonymous } \\
\text { SNV }\end{array}$ & p.Q902K & - & $\mathrm{D}, \mathrm{D}, \mathrm{N}$ \\
\hline & & c.C2689G & exonic & $\begin{array}{c}\text { nonsynonymous } \\
\text { SNV }\end{array}$ & p.R897G & - & $\mathrm{D}, \mathrm{T}, \mathrm{N}$ \\
\hline & & c.A2705G & exonic & $\begin{array}{c}\text { nonsynonymous } \\
\text { SNV }\end{array}$ & p.Q902R & - & $\mathrm{D}, \mathrm{D}, \mathrm{N}$ \\
\hline & HER3 & c.A3355T & exonic & $\begin{array}{c}\text { nonsynonymous } \\
\text { SNV }\end{array}$ & p.S1119C & - & $\mathrm{D}, \mathrm{T}, \mathrm{N}$ \\
\hline & & c.G2606A & exonic & $\begin{array}{c}\text { nonsynonymous } \\
\text { SNV }\end{array}$ & p.S869N & rs 143021252 & $\mathrm{~B}, \mathrm{~T}, \mathrm{~N}$ \\
\hline & & IVS27-7C $>\mathrm{T}$ & intronic & - & - & rs812826 & - \\
\hline & HER4 & $\begin{array}{l}\text { IVS24- } \\
\text { 7delCTTT }\end{array}$ & splicing & - & - & rs138150601 & - \\
\hline & & IVS13-12A $>$ T & intronic & - & - & rs78812564 & - \\
\hline & & IVS25-53delC & intronic & - & - & rs 142227938 & - \\
\hline & & IVS21+81insA & intronic & - & - & rs 141267844 & - \\
\hline & & IVS16-18delT & intronic & - & - & - & - \\
\hline
\end{tabular}

HVAR outputs: B, benign; P, potentially deleterious; D, probably deleterious; SIFT outputs: T, tolerated; D, deleterious; MutationAssessor outputs: N, neutral; L, low; M, medium; H, high; - , unknown

immunohistochemistry analysis showed that HER4 was localized exclusively in the nuclei and cytoplasm of all trastuzumab-resistant subclones and, in particular, was highly expressed in KKP HR (Figure 5B).

\section{Relationship between specific genetic variations and change in HER2 and HER3 receptor structure}

We analyzed the exonic variants of target genes detected by NGS to investigate their role in the onset of resistance to trastuzumab (Figure 6). None of the cell lines showed exonic genetic variants for HER4 or IQGAP1 genes. In addition, no intronic variants were found in the IQGAP1 gene (data not shown). Once again, the cells showing the highest number of variants of all parental cells or subclones were NCI N87, which was also the most sensitive to trastuzumab. In particular, 5 mutations were located in a region in the predominantly $\alpha$-helical C-terminal lobe between residues 898 and 906 of HER2 isoform 37 and between residues 897 and 902 of HER2 isoform 48. Its resistant subclone, NCI N87 HR, did not acquire new genetic variants. Conversely, this subclone showed the loss of 3 variants with respect to 
the parental line. In particular, the genetic variants were located in clusters between residues 897 and 902 in the C-terminal lobe of HER2 isoform 48, and the mutation in position 759 belonging to the N-terminal lobe of HER3. Conversely, the trastuzumab-resistant subclones KKP $\mathrm{HR}$ and $\mathrm{AKG} \mathrm{HR}$ acquired one and 2 genetic variants, respectively, compared to their parental cell lines, all located between residues 898 and 906 in a region in the predominantly $\alpha$-helical C-terminal lobe of HER2 isoform 37 (Figure 6A). The crystal structure of the kinase domain of HER2 (HER2-KD) in complex with SYR127063 (PDB code 3PP0) is shown in Figure 6B.
A

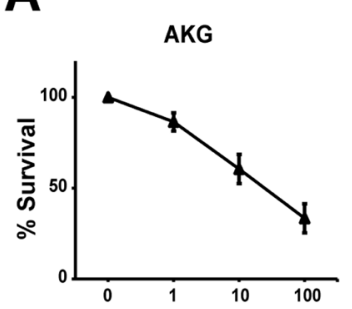

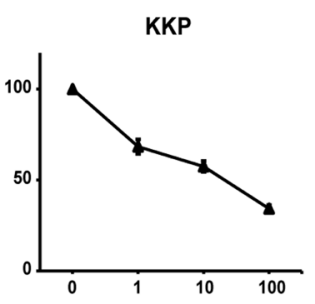
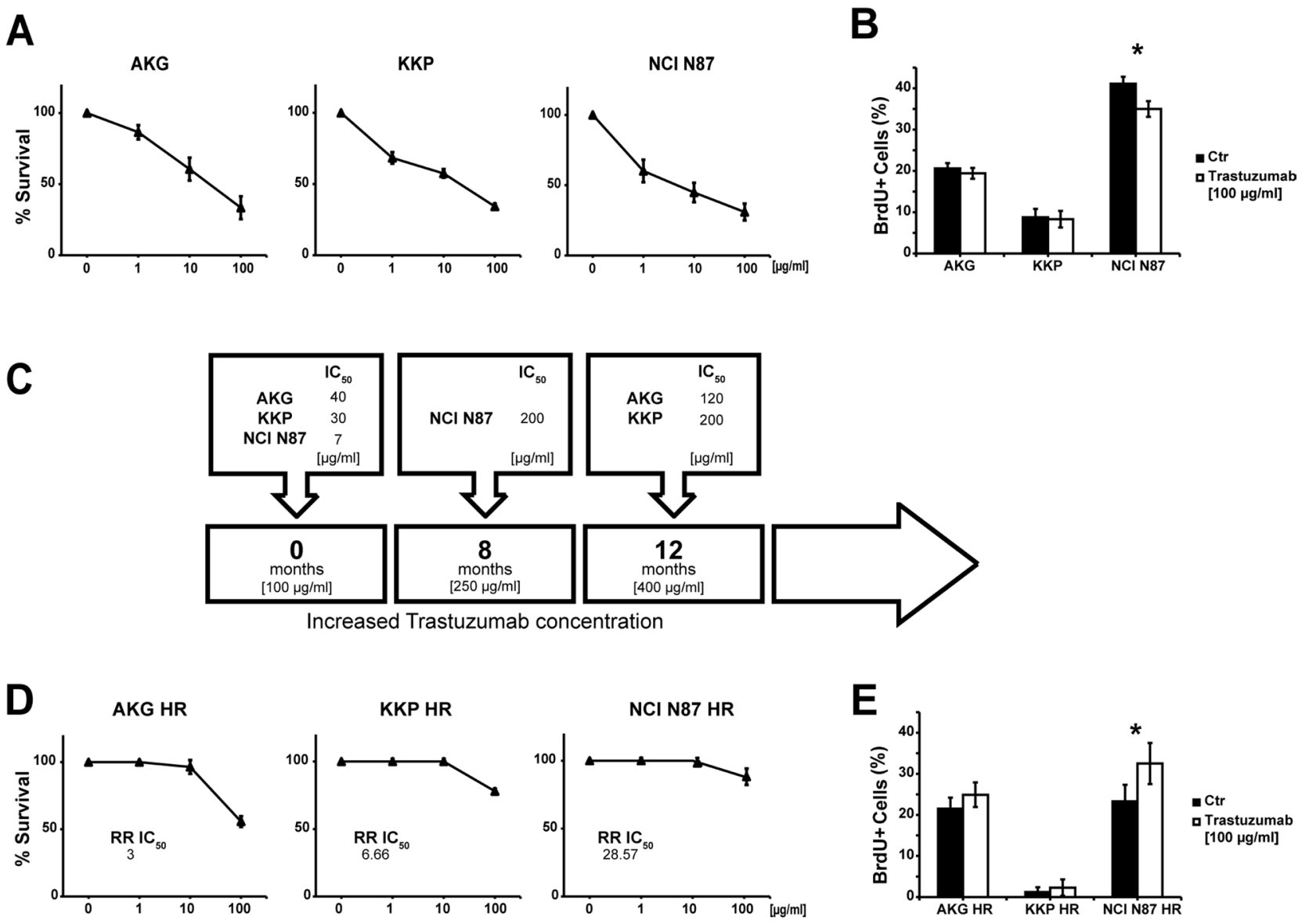

$\mathbf{F}$

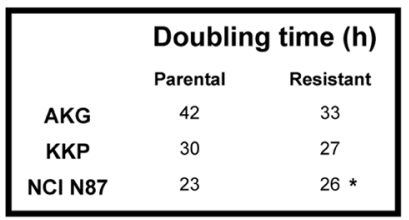

G

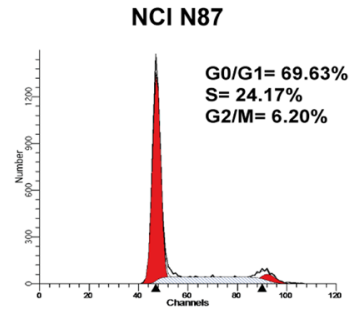

NCI N87 HR

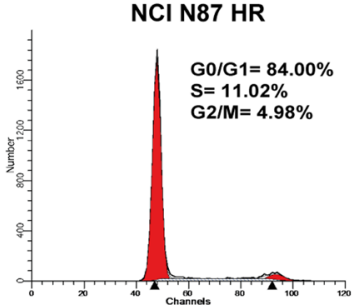

Figure 2: Induction of trastuzumab-resistance in gastric cancer cell lines. A. Trastuzumab sensitivity curves in parental cell lines evaluated by clonogenic assay. Each point indicates the mean of at least three experiments. The standard deviation never exceeded $5 \%$. B. Percentage (median value) of BrdU-positive cells after trastuzumab treatment $(100 \mu \mathrm{g} / \mathrm{ml})$. Values are the mean $\pm \mathrm{SD}$ of three independent experiments. ${ }^{*}$ significance at $\mathrm{p}<0.05$ by t-test. $\mathbf{C}$. The induction timeline of trastuzumab resistance. Resistant cells were generated by continuous treatment with trastuzumab for more than 8 months. D. Trastuzumab sensitivity curves in resistant cell lines evaluated by clonogenic assay. Each point indicates the mean of at least three experiments. Standard deviation never exceeded 5\%. E. Percentage (median value) of BrdU-positive cells after trastuzumab treatment $(100 \mu \mathrm{g} / \mathrm{ml})$. Values are the mean \pm SD of three independent experiments. * significance at $\mathrm{p}<0.05$ by t-test. F. Doubling times of parental and resistant cell lines. G. Cell cycle analysis of NCI N87 and NCI N87 HR by flow cytometry. Data are expressed as a percentage of distribution in each cell-cycle phase. 


\section{DISCUSSION}

In gastric cancer patients, HER2/neu gene expression is an independent prognostic factor, and overexpression of the HER2 protein is correlated with poor prognosis and short-term survival $[38,39]$. The effectiveness of trastuzumab and its subsequent approval as first-line treatment for HER2-overexpressing metastatic gastric cancer confirmed the importance of this receptor in gastric cancer. However, as already observed in other tumors, the majority of patients who initially show sensitivity to trastuzumab develop resistance within one year [17]. Aberrant HER2 activity and the activation of the HER2 receptor in human gastric tumors leads to receptor heterodimerization, mainly with HER3 and HER4 receptors [40], triggering a complex signal transduction cascade that modulates cancer cell survival, proliferation, mobility and invasiveness [41].

The main aim of our work was to investigate resistance mechanisms to trastuzumab in preclinical models of human gastric cancer. For this purpose we created trastuzumab resistant subclones starting from 3 HER2-overexpressing gastric cancer cell lines (AKG, KKP and NCI-N87 cells) with a high sensitivity to trastuzumab. These lines also expressed other HER family receptor members and showed genetic variants of HER2, HER3 and HER4.

After 8-12 months' exposure to increasing concentrations of trastuzumab, we successfully obtained trastuzumab-resistant AKG HR, KKP HR and NCI N87 HR subclones that grew in culture medium supplemented with high concentrations of the drug (up to $400 \mu \mathrm{g}$ /
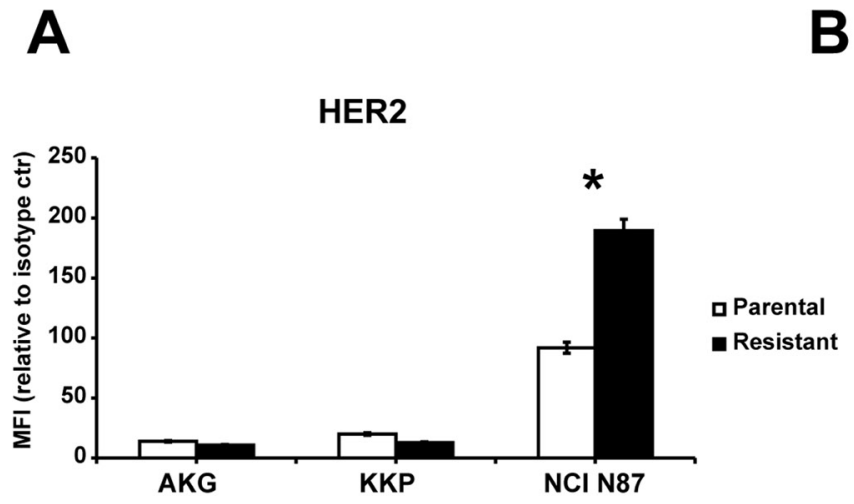

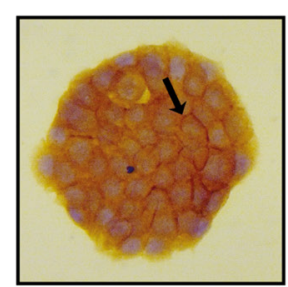

AKG HR

HER2

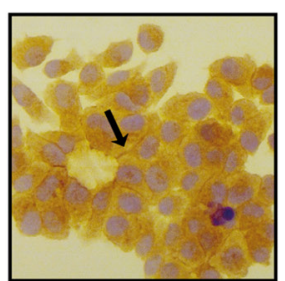

KKP HR

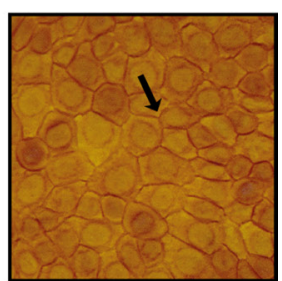

$\mathrm{NCl}$ N87 HR
C

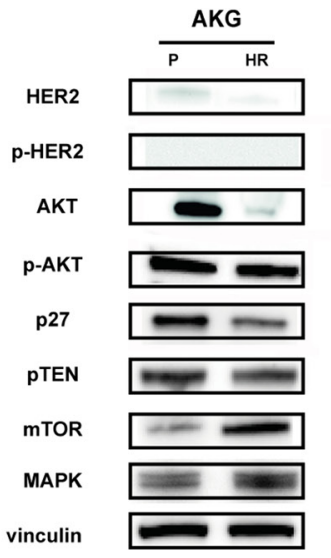

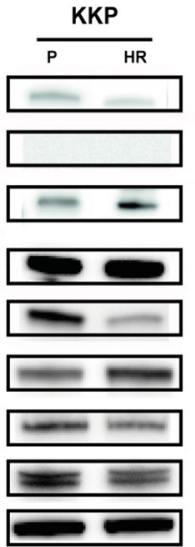

185 kd

$185 \mathrm{kd}$

$60 \mathrm{kd}$

$60 \mathrm{kd}$

27 kd

$54 \mathrm{kd}$

289 kd

$42 / 44 \mathrm{kd}$

$125 \mathrm{kd}$

Figure 3: Characterization of trastuzumab targeting in resistant subclones: AKG HR, KKP HR and NCI N87 HR cells. A. HER2 protein levels on the cell surface were quantified by flow cytometry and expressed as mean fluorescence intensity (MFI) relative to isotype control. Statistical significance was denoted as * $p<0.05$. B. HER2 staining by IHC in gastric cancer cell lines. Sample reactivity was evaluated by light microscopy $(\times 200$ magnification) by two independent observers. Marker positivity was evaluated in a semiquantitative manner, as described in the Materials and Methods section. C. Western blotting showed HER2, p-HER2, AKT, p-AKT, p27, PTEN, mTOR and MAPK protein expression in parental (P) and resistant (HR) cell lines. Vinculin expression indicated equal loading. All gels were run under the same experimental conditions and the experiments were repeated 3 times. The representative images were cropped and shown. 


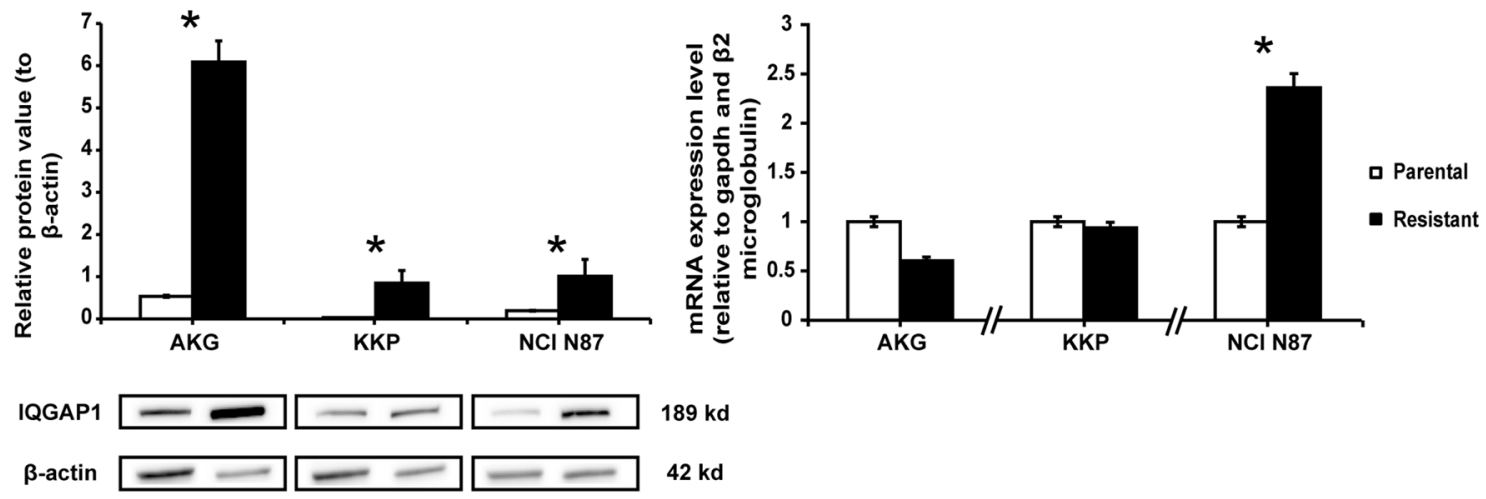

B

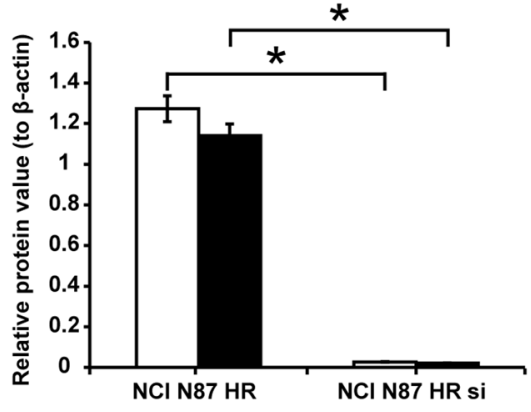

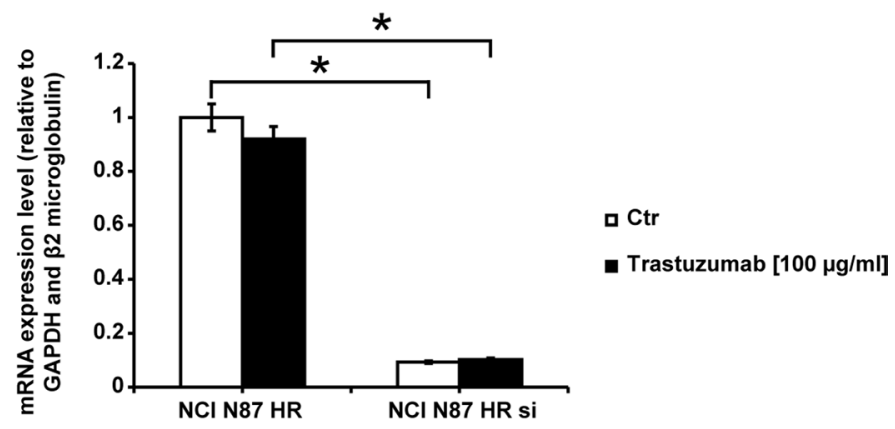

C

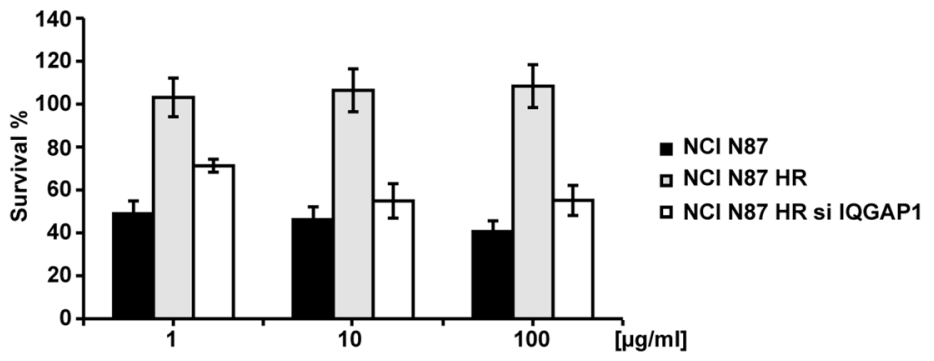

$\mathrm{NCl}$ N87
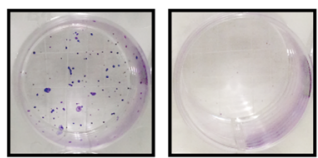

$+$
$\mathrm{NCl}$ N87 HR

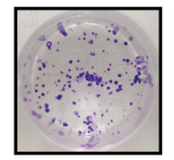

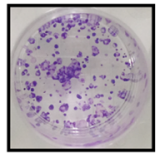

$+$
NCI N87 HR si
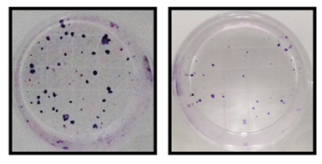

$+\quad$ Trastuzumab $[100 \mu \mathrm{g} / \mathrm{ml}]$

Figure 4: Trastuzumab sensitivity in subclone NCI N87 HR restored by IQGAP1 knockdown. A. IQGAP1 expression. The left panel shows the western blot of IQGAP1 in gastric cancer cell lines. $\beta$-actin expression indicated equal loading. Densitometric quantification of total IQGAP1 was calculated using Quantity One Software. All gels were run under the same experimental conditions and the experiments were repeated 3 times. The representative images were cropped and shown. The right graph shows IQGAP1 mRNA expression levels in resistant cells quantified with respect to parental cells and normalized to GAPDH and $\beta 2$ microglobulin. Data are presented as mean +- SD. * $\mathrm{p}<0.05$. B. IQGAP1 silencing. IQGAP1 protein expression levels (left graph) and IQGAP1 mRNA levels (right graph) in NCI N87 HR and NCI N87 HR IQGAP1-silenced before and after a $72 \mathrm{~h}$-exposure to $100 \mu \mathrm{g} / \mathrm{ml}$ of trastuzumab. Western blot analysis of IQGAP1 was normalized to $\beta$-actin. IQGAP1 mRNA levels were measured by Real Time PCR and normalized to GAPDH and $\beta 2$ microglobulin. Values are the mean $\pm \mathrm{SD}$ of three independent experiments. C. The effect of IQGAP1 knockdown in NCI N87 HR cells was investigated in colony formation experiments carried out $72 \mathrm{~h}$ after transfection. The upper panel illustrates relative growth curves (means +- SD) and the bottom panel shows representative colony photos. 
ml). Cell growth curves, BrdU incorporation and cell cycle analyses revealed that the biological features of trastuzumab-resistant cells differed from those of parental cells. In particular, the NCI N87 HR subclone grew more slowly, had a lower proliferative activity and showed a higher percentage of cells in $\mathrm{G}_{0} / \mathrm{G}_{1}$ phase and a lower percentage in S phase than NCI N87 cells. Similar results were reported by Zou et al. [42] who were the first group to obtain a trastuzumab-resistant subclone of NCI-N87 (N87 NCI/TR). In addition, our flow cytometry analyses revealed an increase in membrane HER2 levels only in the NCI N87 HR subclone with respect to its parental cells. We also detected a marked increase in p-HER2, AKT, p-AKT and MAPK protein levels and a reduction in p27 protein expression in NCI N87 HR cells. These results are in agreement with those from previous studies in which trastuzumab was reported to inhibit HER2+ tumor growth by stimulating endocytosis and degradation of the receptor, with subsequent impairment of downstream signaling through PI3K/AKT and MAPK cascades [43]. It was also recently reported that increased PI3K/AKT and MAPK cascade signaling inhibits p27 expression [43-46].

White et al. revealed that IQGAP1 governs trastuzumab function in HER2-overexpressing breast cancer. In particular, they reported that, in IQGAP1silenced breast cancer cells, trastuzumab increased its capacity to decrease HER2 expression and HER2stimulated activation of the PI3K/AKT cascade [37].

A

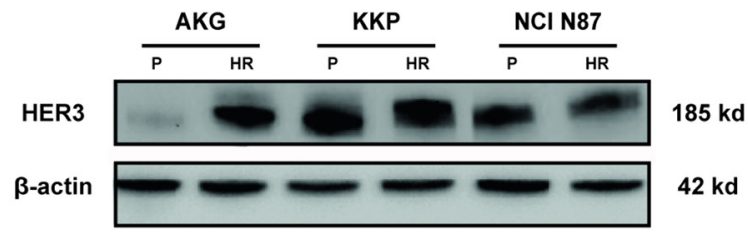

B

HER3

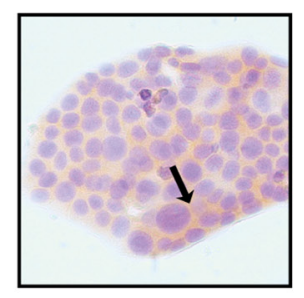

AKG

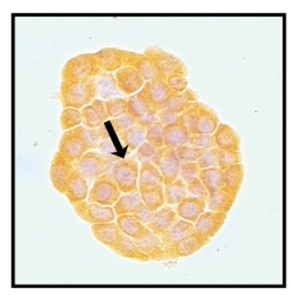

AKG HR

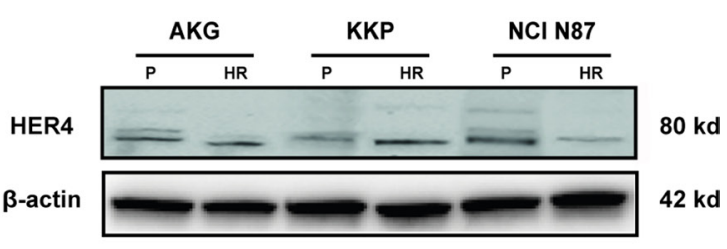

HER4

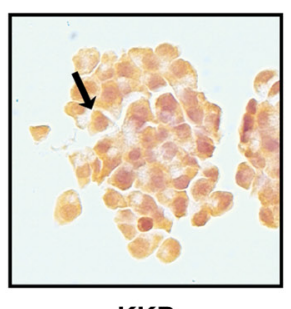

KKP

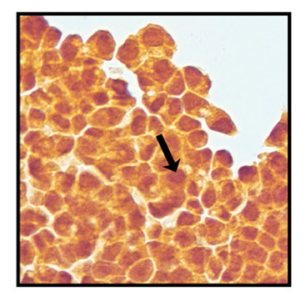

KKP HR

Figure 5: Characterization of resistant subclones: AKG HR, KKP HR and NCI N87 HR cells. A. HER3 and HER4 protein levels in parental cell lines (P) and their derivative subclones (HR) evaluated by western blot. The representative images were cropped and shown. Statistical significance was denoted as $* p<0.05$. B. HER3 and HER4 staining by IHC in AKG and KKP cells, respectively and in their derivative resistant subclones. Sample reactivity was evaluated by light microscopy $(\times 200$ magnification $)$ by two independent observers. Marker positivity was evaluated in a semiquantitative manner, as described in the Materials and Methods section. 
We also investigated the presence of genetic variants potentially involved in acquired trastuzumab resistance. No genetic variants of the IQGAP1 gene were found in any of the studied cell lines. Furthermore, NGS analysis revealed that the resistant clone NCI N87 HR did not acquire additional gene variants with respect to the parental line. Conversely, KKP HR and AKG HR acquired one and two genetic variants, respectively, compared to their parental cell lines, and all were located in the C-terminal lobe of HER2, in a portion of the molecule called $\alpha$ F-helix. $\alpha$ F-helix, a highly hydrophobic component located in the middle of the C-lobe, plays a central role in anchoring key hydrophobic motifs. In particular, it forms the base of $\mathrm{C}$ - and $\mathrm{R}$-spines, two motifs previously described by Kornev et al., [50, 51] which coordinate the $\mathrm{N}$ - and C-lobe movements of the kinase domain in the active conformation of the protein [52]. Given that both motifs are highly conserved through different types of active protein kinases, the assembly and anchorage of the spines to $\alpha \mathrm{F}$ helix could be an important regulatory element. Furthermore, the activation loop, another important portion of the kinase domain, is firmly anchored to the hydrophobic $\alpha \mathrm{F}$ helix. This is the most flexible part of the activation segment and requires phosphorylation to activate and increase the enzymatic activity of protein kinases, including ErbB family members $[53,54]$. The genetic variants detected by our NGS analysis have never been reported before and may serve to maintain the active conformation of the HER2 receptor.

In conclusion, our study provides evidence of the existence of different mechanisms of resistance to trastuzumab in human gastric cancer. We also discovered that IQGAP1 is involved in trastuzumab resistance in gastric cancer cell lines and identified 2 new mutations of the HER2 gene that may be correlated with acquired resistance to the drug. Further studies are needed to explore these issues.

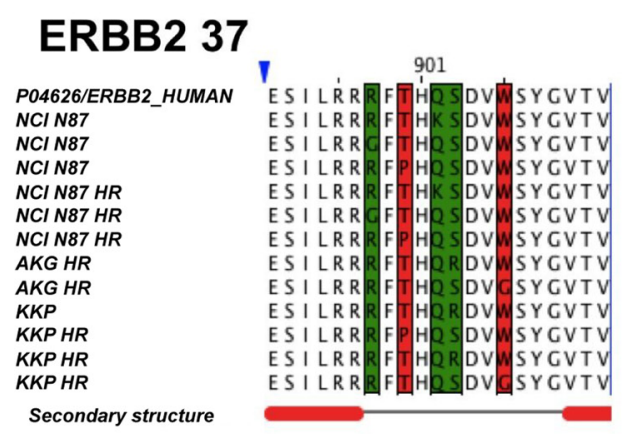

B

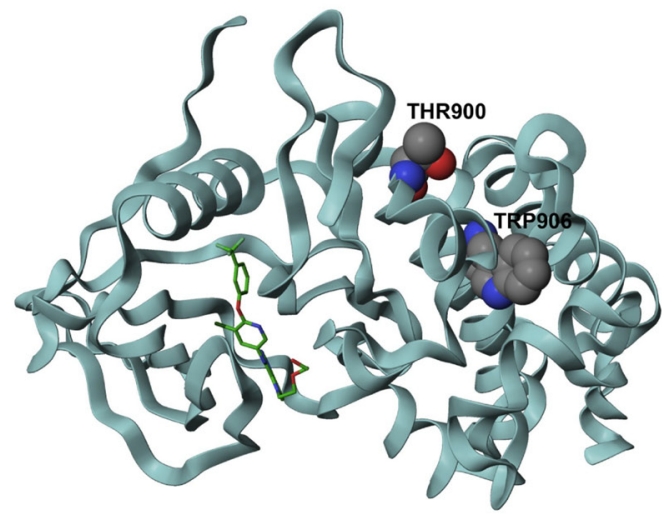

\begin{tabular}{|c|c|c|c|c|c|}
\hline & & 900 & 1056 & 106 & \\
\hline$P 04626 / E$ & LESI LR & R FTHF & SDV́WSYGGGDLT & LGLPSEGATLER & KT L SPG \\
\hline $\mathrm{NCl} \mathrm{N87}$ & LES I LR & RFTH & SSDVWSYGGGDLT & LGLEP S E|GATLER & KT LSPG \\
\hline NCI N87 & LES I LR & RFTH & SDVWSYGGCDLT & $\angle G L E P S E \mid G A T L E R$ & KT LSPC \\
\hline$A K G$ & LESILR & RFTHK & SDVWSYGCGDLT & GLEPSEIGATLER & KT L SPC \\
\hline$A K G$ & LES I LR & R FTH & SDVWSYGGGDLT & LGLEP S E[GATLER & A T L SPG \\
\hline$A K G H R$ & LES I LR & R FTH & SDVWSYGGGDLT & LGLEPSE|GATLER & $K T L S P G$ \\
\hline KKP & LES I LR & RFTH & 2 SDVWSYGGCDLT & LGLEPSE|GATLER & KT L SPG \\
\hline$K K P H R$ & LES ILR & & 2 S DVWS Y|GGCDLT & LG L EP S E|CAT LER & $\mathbb{A} K T$ L S P G \\
\hline
\end{tabular}

\section{ERBB3}

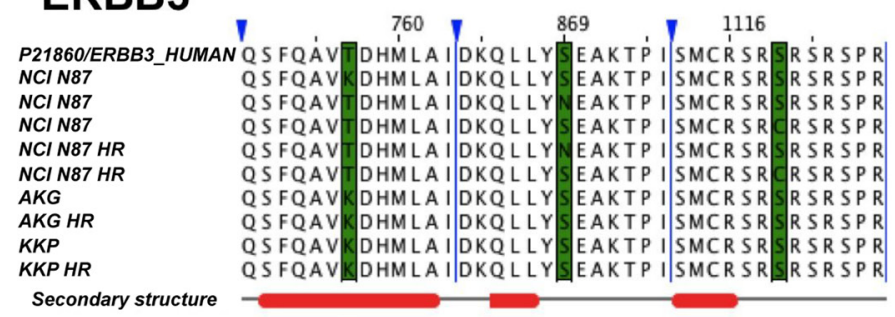

Figure 6: Comparison of sequence alignment between parental and trastuzumab resistant subclones. A. Sequence alignments of HER2 37, HER2 48 isoforms and HER3 highlights mutations in the cell lines under investigation. The red columns represent mutations associated with resistant cells, while green columns represent other kinds of mutations. Triangles denote hidden columns in the sequence. Secondary structure prediction denotes $\alpha$-helix (red) and $\beta$-strand (green). B. The crystal structure of the kinase domain of HER2 (HER2-KD) in complex with SYR127063 (PDB code 3PP0). The ligand (green) binds to the HER2 ATP binding site. The mutations that confer resistance are located in residues 900 and 906 (in CPK notation) in a region located at the C-terminal lobe of the HER2-KD, which is predominantly $\alpha$-helical. 


\section{MATERIALS AND METHODS}

\section{Cell lines}

The study was performed on two cell lines (AKG, KKP) derived from human gastric adenocarcinoma (intestinal type), established and characterized in our laboratory [55,56], and one commercial cell line obtained from a liver metastasis of a well differentiated gastric carcinoma (NCI-N87) and purchased from the American Type Culture Collection (ATCC, Rockville, MD, USA). Cell lines were maintained as a monolayer at $37^{\circ} \mathrm{C}$ and subcultured weekly. The culture medium was composed of DMEM/Ham's F12 (1:1) supplemented with fetal calf serum $(10 \%)$, glutamine $(2 \mathrm{mM})$, non-essential amino acids (1\%) (Mascia Brunelli S.p.A., Milan, Italy), and insulin $(10 \mathrm{mg} / \mathrm{ml})$ (Sigma-Aldrich, St. Louis, MO, USA). Cells were used in the exponential growth phase in all experiments.

\section{Doubling time}

For growth analysis, cells were plated in 12-well plates in triplicate at a concentration of $2 \times 10^{4}$ cells/ well. Cells were collected and counted for the first 7 days after plating. Trastuzumab (Herceptin ${ }^{\circledR}$ ) was purchased by the Oncology Pharmacy of our institute (IRST IRCCS). Proliferation doubling time was determined by the following formula: $\log 2(\mathrm{Cv} / \mathrm{Cs})$, where $\mathrm{Cv}$ is the number of viable cells at harvest and Cs is the number of cells seeded. The sum of all previous population doublings determined the cumulative population doubling level at each passage. The Trypan blue exclusion test was used to evaluate the percentage of viable cells, which always exceeded $98 \%$ for the duration of the experiments.

\section{Generation of trastuzumab-resistant subclones}

We induce trastuzumab resistance by culturing trastuzumab-sensitive gastric cancer cell lines in the presence of progressively increasing doses of trastuzumab over a period of 12 months. The final concentration of trastuzumab used was $250 \mu \mathrm{g} / \mathrm{ml}$ for the trastuzumabresistant subclone NCI-N87 HR and $400 \mu \mathrm{g} / \mathrm{ml}$ for the subclones AKG HR and KKP HR.

\section{Immunohistochemistry}

Cells were seeded in sterile culture slides (BD, Falcon, New Jersey, USA) and cultured in a humidified $\mathrm{CO} 2$ incubator for $72 \mathrm{~h}$. They were then fixed in $4 \%(\mathrm{v} / \mathrm{v})$ paraformaldehyde for $20 \mathrm{~min}$ and blocked for endogenous peroxidase activity with a $3 \%$ hydrogen peroxide solution. Antigen unmasking was performed using citrate buffer $\mathrm{pH} 6$ for $40 \mathrm{~min}$ at $98.5^{\circ} \mathrm{C}$. Rabbit monoclonal anti-human antibodies for HER3 (Cell Signaling Technology, Inc., Danvers, MA, USA) and HER4 (Santa Cruz Biotechnology, Dallas, Texas, USA) were used at a dilution of 1:250. Mouse monoclonal anti-human antibody for HER2 (Dako Corporation, Carpenteria, CA, USA) was used at a dilution of 1:100. Antibodies were incubated for $60 \mathrm{~min}$ at room temperature. Slides were washed with phosphate buffered saline (PBS), incubated with a universal biotinylated secondary antibody for 15 min and rinsed in PBS. They were then incubated with streptavidin-peroxidase conjugate (LSAB + Kit; Dako Corporation) for $15 \mathrm{~min}$. Slides were rinsed again in PBS and antibody binding was detected by staining with diaminobenzidine/hydrogen peroxidase chromogen solution (DAB + liquid substrate-chromogen solution; Dako Corporation). Finally, the sections were rinsed in deionized water, counterstained by Mayer's hematoxylin, and mounted by Eukitt (Bio-Optica, Milan, Italy). Sample reactivity was evaluated by light microscopy $(\times 200)$ by two independent observers. Marker positivity was evaluated semi-quantitatively. Staining was evaluated in terms of the localization (nuclear, cytoplasmatic and membrane) of the selected proteins and the percentage of positive cells.

\section{Clonogenic assay}

Following a 72-h exposure to trastuzumab, 500 cells were seeded in $10-\mathrm{cm}^{2}$ dishes in $500 \mathrm{ml}$ of medium. After 14 days, the resulting colonies were fixed and stained using $0.5 \%$ crystal violet in $25 \%$ methanol; colonies with more than 50 cells were quantified under inverted microscope (Olympus IX51 microscope, Olympus Corporation, Tokyo, Japan) by two independent observers. Five series of samples were prepared for each treatment dose [57].

\section{Cytofluorimetric analysis}

Flow cytometric analysis was performed using a FACS Canto flow cytometer (Becton Dickinson, San Diego, CA, USA) equipped with $488 \mathrm{~nm}$ (blue) and 633 (red) lasers. Data acquisition and analysis were performed using FACSDiva (Becton Dickinson) and ModFit 2.0 (DNA Modelling System, Verity Software House, Inc., Topsham, ME, USA). Samples were run in triplicate and 10,000 events were collected for each replica. Data were the average of three experiments, with errors under $5 \%$.

\section{Cell cycle distribution}

After exposure to trastuzumab, cells were fixed in $70 \%$ ethanol, stained with propidium iodide $(10 \mathrm{mg} /$ ml, MP Biomedicals, Verona, Italy), RNAse (10 kunits/ $\mathrm{ml}$, Sigma-Aldrich) and NP40 (0.01\%, Sigma Aldrich) overnight at $37 \mathrm{C}^{\circ}$ in the dark, and analyzed by flow 
cytometry. Data were expressed as fractions of cells in the different cycle phases.

\section{Bromodeoxyuridine (BrdU) assay}

After treatment with trastuzumab100 $\mu \mathrm{g} / \mathrm{ml}$, the cell culture medium was supplemented with $60 \mu \mathrm{M}$ of $\mathrm{BrdU}$ and incubated for an additional $5 \mathrm{~h}$. At the end of the incubation time, cells were fixed, incubated for 25 min with $2 \mathrm{M}$ of HCL and then washed with borax 0.1 M. Samples were incubated with anti-BrdU antibody 1:1000 (Sigma-Aldrich) for $60 \mathrm{~min}$. After incubation with FITC-conjugated antibody (goat anti-mouse 1:250, Dako Corporation), cells were stained with $5 \mathrm{mg} / \mathrm{ml}$ of propidium iodide for $2 \mathrm{~h}$ at $4^{\circ} \mathrm{C}$ before flow cytometry acquisition.

\section{Immunophenotypic analysis}

Cells were fixed and immunophenotyping was performed using anti-HER2 (1:100) (Invitrogen, Life Technologies, Monza, Italy) antibody for $30 \mathrm{~min}$ at $4{ }^{\circ} \mathrm{C}$. After three washes, cells were incubated with RPEconjugated goat anti-rabbit antibody 1:250 (Invitrogen) for $60 \mathrm{~min}$ in the dark. Appropriate isotype control was included for each sample.

\section{Western blot}

Cells were treated according to the previously described western blot procedure [58]. The following primary antibodies were used: anti-IQGAP1 (1:400), antiHER2 (1:800) (Invitrogen, Thermo Fisher Scientific); anti-actin (1:1000) (Sigma-Aldrich); anti-HER4 (1:1000) (Abcam, Cambridge, UK); anti-vinculin (1:1000) (Thermo Fisher Scientific); anti-p27 (1:1000) (BD Biosciences, Milan, Italy); anti-HER3 (1:1000), anti-PTEN (1:1000), anti-mTOR (1:600), anti-MAPK (1:1000), anti-AKT (1:1000), anti-phospho-AKT $\left(\operatorname{Ser}^{473}\right)(1: 1000)$ and antiphospho-HER2 (Tyr ${ }^{1221 / 1222}$ ) (1:1000) (Cell Signaling Technology). Precision Plus Protein ${ }^{\mathrm{TM}}$ WesternC $^{\mathrm{TM}}$ Standards were used as molecular weight standards (BioRad \#161-0376). Quantity One Software (Bio-Rad) was used for analysis.

\section{Small interfering RNA transfection}

Silencer ${ }^{\circledR}$ Select Validated siRNA (Ambion, Carlsbad, CA, USA) was utilized for IQGAP1 silencing. A validated Universal Negative ControlTM (Invitrogen) was used as a control for transfection. The siRNA oligonucleotide showing the highest knockdown efficiency of IQGAP1 mRNA in the NCIN87cell line was used for the experiments. Cells were treated according to the previously described procedure [59]. Cells were treated after $72 \mathrm{~h}$.

\section{RNA extraction and real-time RT-PCR}

Total RNA was extracted from cell lines using TRIzol $^{\circledR}$ reagent according to the manufacturer's instructions (Invitrogen). Reverse transcription (RT) reactions were performed using an iScript TM cDNA Synthesis kit (Bio-Rad Laboratories). mRNA expression was analyzed by quantitative Real-Time PCR using the 7500 Real Time PCR system (Applied Biosystems, Thermo Fisher Scientific). The following TaqMan assays (Applied Biosystems, Thermo Fisher Scientific) were used: IQGAP1 (Hs00896595_m1) and its relative gene expression was normalized to glyceraldehyde 3-phosphate dehydrogenase (GAPDH Hs03929097g1) and B2microglobulin (Hs00984230_m1). Data showed the average of triplicates \pm standard deviation (SD) and were representative of three independent experiments.

\section{DNA extraction and next-generation sequencing (NGS)}

Genomic DNA was extracted using QIAamp DNA MiniKit (Qiagen, Hilden, Germany) as per the manufacturer's protocol. DNA quality was evaluated with High Sensitivity DNA Analysis Kit on Bioanalyzer 2100 (Agilent Technologies, Santa Clara, CA, USA) and quantified using Qubit dsDNA BR Assay Kit (Invitrogen). DNA from these cell lines was subjected to target sequencing using a custom panel purchased from Agilent Technologies.

Sequences were achieved by designing primers to capture the entire coding region, exon-intron boundaries $( \pm 10 \mathrm{bp})$ and the promoter region of 4 genes using the Agilent HaloPlex Target Enrichment System (Table 3). Quantified libraries were sequenced on the Illumina MiSeq platform (San Diego, CA, USA) using 2 X 151 bp in pairend mode and run on an Illumina V2 sequencing flow cell.

Raw demultiplexed reads from MiSeq sequencer were aligned against the human reference genome hg19 with BWA MEM [60]. GATK version 3.2.2 was used to recalibrate base qualities and realign aligned reads around indels [61]. Regions with coverage of less than or equal to 200x were discarded for downstream analyses. Somatic variant analysis was used to detect mutations: single nucleotide variants (SNVs) were identified using MuTect version 1.1.7 with standard parameters, and GATK IndelGenotyperV2 (with minFraction $=0.01$ and $\operatorname{minCnt}=5$ ) was used to detect Indels. Genomic and functional annotation of detected variants was made by Annovar $[62,63]$. Coverage statistics were performed by Depth of Coverage utility of GATK. BASH and R custom scripts were used to obtain the list of low coverage (200X) regions per sample.

Sequencing runs produced a total of $36,646,538$ reads, of which $94.6 \%$ mapped on the hg19 human 
Table 3: Genes selected for next generation sequencing (NGS) analysis

\begin{tabular}{|c|c|c|c|c|}
\hline Gene & entrez ID & cytoband & genomic coordinates & number of exons \\
\hline HER2 & 2064 & $17 q 12$ & $\operatorname{chr17:37844316-37884317}$ & $\operatorname{All}(31)+5^{\prime}$ UTR \\
\hline HER3 & 2065 & $12 \mathrm{q} 13.2$ & chr12:56473788-56495859 & All(28)+5'UTR \\
\hline HER4 & 2066 & $2 q 34$ & chr2:212248319-213403372 & $\operatorname{All}(28)+5$ 'UTR \\
\hline$I Q G A P 1$ & 8826 & $15 q 26.1$ & $\operatorname{chr15:90931452-91043360}$ & All(38) \\
\hline
\end{tabular}

reference genome, with a median coverage depth of 2779 , $73 \mathrm{X}$ per sample. Only candidate somatic alterations with a read depth of at least 200 and a mutant allele fraction $>1 \%$ were considered. Sequence results from parental and resistant subclones were compared to identify putative somatic mutations at the basis of the development of resistance.

\section{Molecular modeling}

The UniProt sequences P04626, P21860 and P46940 were taken as a reference for HER2, HER3 ad IQGAP1, respectively. Jalview V. 2.8.2 was used to obtain sequence alignments. The web service Clustal Omega was used with its default settings. Percentage identity coloring was used to generate figures. Three-dimensional figures were generated using an academic version of Maestro software V. 10.1.013.

\section{Statistical analysis}

All experiments were performed at least three times. Quantifiable data were derived from three independent experiments. Statistical analysis was carried out using GRAPH PAD PRISM 5.0 software by applying the Student $t$ test for 2-group comparisons. Differences were considered significant at $\mathrm{p}<0.05$.

\section{ACKNOWLEDGMENTS}

The authors thank Prof. Romano Danesi for his invaluable scientific contribution and Ursula Elbling for editing the manuscript.

\section{CONFLICTS OF INTEREST}

The authors declare that they have no conflicts of interest.

\section{REFERENCES}

1. Torre LA, Bray F, Siegel RL, Ferlay J, Lortet-Tieulent J, Jemal A. Global cancer statistics, 2012. CA: a cancer journal for clinicians. 2015.
2. LAUREN P. The Two Histological Main Types of Gastric Carcinoma: Diffuse and So-Called Intestinal-Type Carcinoma. an Attempt at a Histo-Clinical Classification. Acta Pathologica et Microbiologica Scandinavica. 1965; 64: 31-49.

3. Cunningham D, Allum WH, Stenning SP, Thompson JN, Van de Velde CJ, Nicolson M, Scarffe JH, Lofts FJ, Falk SJ, Iveson TJ, Smith DB, Langley RE, Verma M, et al. Perioperative chemotherapy versus surgery alone for resectable gastroesophageal cancer. The New England journal of medicine. 2006; 355: 11-20.

4. Smyth EC, Cunningham D. Gastric cancer in 2012: Defining treatment standards and novel insights into disease biology. Nature reviews. Clinical oncology. 2013; 10: 73-74.

5. Shah MA, Schwartz GK. Treatment of metastatic esophagus and gastric cancer. Seminars in oncology. 2004; 31: 574-587.

6. Ohtsu A, Shimada Y, Shirao K, Boku N, Hyodo I, Saito H, Yamamichi N, Miyata Y, Ikeda N, Yamamoto S, Fukuda H, Yoshida S, Japan Clinical Oncology Group Study (JCOG9205). Randomized phase III trial of fluorouracil alone versus fluorouracil plus cisplatin versus uracil and tegafur plus mitomycin in patients with unresectable, advanced gastric cancer: The Japan Clinical Oncology Group Study (JCOG9205). Journal of clinical oncology. 2003; 21: 54-59.

7. Dickson JL, Cunningham D. Systemic treatment of gastric cancer. European journal of gastroenterology \& hepatology. 2004; 16: 255-263.

8. Yano T, Doi T, Ohtsu A, Boku N, Hashizume K, Nakanishi M, Ochiai A. Comparison of HER2 gene amplification assessed by fluorescence in situ hybridization and HER2 protein expression assessed by immunohistochemistry in gastric cancer. Oncology reports. 2006; 15: 65-71.

9. Kim MA, Lee HJ, Yang HK, Bang YJ, Kim WH. Heterogeneous amplification of ERBB2 in primary lesions is responsible for the discordant ERBB2 status of primary and metastatic lesions in gastric carcinoma. Histopathology. 2011; 59: 822-831.

10. Marx AH, Tharun L, Muth J, Dancau AM, Simon R, Yekebas E, Kaifi JT, Mirlacher M, Brummendorf TH, 
Bokemeyer C, Izbicki JR, Sauter G. HER-2 amplification is highly homogenous in gastric cancer. Human pathology. 2009; 40: 769-777.

11. Fassan M, Mastracci L, Grillo F, Zagonel V, Bruno S, Battaglia G, Pitto F, Nitti D, Celiento T, Zaninotto G, Fiocca R, Rugge M. Early HER2 dysregulation in gastric and oesophageal carcinogenesis. Histopathology. 2012; 61: 769-776.

12. Fassan M, Pizzi M, Realdon S, Balistreri M, Guzzardo V, Zagonel V, Castoro C, Mastracci L, Farinati F, Nitti D, Zaninotto G, Rugge M. The HER2-miR125a5p/miR125b loop in gastric and esophageal carcinogenesis. Human pathology. 2013; 44: 1804-1810.

13. Jorgensen JT, Hersom M. HER2 as a Prognostic Marker in Gastric Cancer - A Systematic Analysis of Data from the Literature. Journal of Cancer. 2012; 3: 137-144.

14. Bang YJ, Van Cutsem E, Feyereislova A, Chung HC, Shen L, Sawaki A, Lordick F, Ohtsu A, Omuro Y, Satoh T, Aprile G, Kulikov E, Hill J, et al. Trastuzumab in combination with chemotherapy versus chemotherapy alone for treatment of HER2-positive advanced gastric or gastrooesophageal junction cancer (ToGA): a phase 3, open-label, randomised controlled trial. Lancet. 2010; 376: 687-697.

15. Satoh T, Xu RH, Chung HC, Sun GP, Doi T, Xu JM, Tsuji A, Omuro Y, Li J, Wang JW, Miwa H, Qin SK, Chung IJ, et al. Lapatinib plus paclitaxel versus paclitaxel alone in the second-line treatment of HER2-amplified advanced gastric cancer in Asian populations: TyTAN--a randomized, phase III study. Journal of clinical oncology. 2014; 32: 2039-2049.

16. Shimoyama S. Unraveling trastuzumab and lapatinib inefficiency in gastric cancer: Future steps (Review). Molecular and clinical oncology. 2014; 2: 175-181.

17. Okines AF, Cunningham D. Trastuzumab: a novel standard option for patients with HER-2-positive advanced gastric or gastro-oesophageal junction cancer. Therapeutic advances in gastroenterology. 2012; 5: 301-318.

18. Razis E, Bobos M, Kotoula V, Eleftheraki AG, Kalofonos HP, Pavlakis K, Papakostas P, Aravantinos G, Rigakos G, Efstratiou I, Petraki K, Bafaloukos D, Kostopoulos I, et al. Evaluation of the association of PIK3CA mutations and PTEN loss with efficacy of trastuzumab therapy in metastatic breast cancer. Breast cancer research and treatment. 2011; 128: 447-456.

19. Esteva FJ, Guo H, Zhang S, Santa-Maria C, Stone S, Lanchbury JS, Sahin AA, Hortobagyi GN, Yu D. PTEN, PIK3CA, p-AKT, and p-p70S6K status: association with trastuzumab response and survival in patients with HER2positive metastatic breast cancer. The American journal of pathology. 2010; 177: 1647-1656.

20. Zhang S, Huang WC, Li P, Guo H, Poh SB, Brady SW, Xiong Y, Tseng LM, Li SH, Ding Z, Sahin AA, Esteva FJ,
Hortobagyi GN, et al. Combating trastuzumab resistance by targeting SRC, a common node downstream of multiple resistance pathways. Nature medicine. 2011; 17: 461-469.

21. Gallardo A, Lerma E, Escuin D, Tibau A, Munoz J, Ojeda B, Barnadas A, Adrover E, Sanchez-Tejada L, Giner D, Ortiz-Martinez F, Peiro G. Increased signalling of EGFR and IGF1R, and deregulation of PTEN/PI3K/Akt pathway are related with trastuzumab resistance in HER2 breast carcinomas. British journal of cancer. 2012; 106: 1367-1373.

22. Pastuskovas CV, Mundo EE, Williams SP, Nayak TK, Ho J, Ulufatu S, Clark S, Ross S, Cheng E, Parsons-Reponte K, Cain G, Van Hoy M, Majidy N, et al. Effects of antiVEGF on pharmacokinetics, biodistribution, and tumor penetration of trastuzumab in a preclinical breast cancer model. Molecular cancer therapeutics. 2012; 11: 752-762.

23. Garrett JT, Olivares MG, Rinehart C, Granja-Ingram ND, Sanchez V, Chakrabarty A, Dave B, Cook RS, Pao W, McKinely E, Manning HC, Chang J, Arteaga CL. Transcriptional and posttranslational up-regulation of HER3 (ErbB3) compensates for inhibition of the HER2 tyrosine kinase. Proceedings of the National Academy of Sciences of the United States of America. 2011; 108: 5021-5026.

24. Hanker AB, Pfefferle AD, Balko JM, Kuba MG, Young CD, Sanchez V, Sutton CR, Cheng H, Perou CM, Zhao JJ, Cook RS, Arteaga CL. Mutant PIK3CA accelerates HER2driven transgenic mammary tumors and induces resistance to combinations of anti-HER2 therapies. Proceedings of the National Academy of Sciences of the United States of America. 2013; 110: 14372-14377.

25. Xia W, Petricoin EF, 3rd, Zhao S, Liu L, Osada T, Cheng Q, Wulfkuhle JD, Gwin WR, Yang X, Gallagher RI, Bacus S, Lyerly HK, Spector NL. An heregulin-EGFR-HER3 autocrine signaling axis can mediate acquired lapatinib resistance in HER2+ breast cancer models. Breast cancer research: BCR. 2013; 15: R85.

26. Nahta R, Yu D, Hung MC, Hortobagyi GN, Esteva FJ. Mechanisms of disease: understanding resistance to HER2targeted therapy in human breast cancer. Nature clinical practice.Oncology. 2006; 3: 269-280.

27. Mohd Sharial MS, Crown J, Hennessy BT. Overcoming resistance and restoring sensitivity to HER2-targeted therapies in breast cancer. Ann Ocol. 2012; 23: 3007-3016.

28. Kruser TJ, Wheeler DL. Mechanisms of resistance to HER family targeting antibodies. Experimental cell research. 2010; 316: 1083-1100.

29. Vlacich G, Coffey RJ. Resistance to EGFR-targeted therapy: a family affair. Cancer cell. 2011; 20: 423-425.

30. Li X, Duan Y, Qiao C, Zhou T, Yu M, Geng J, Feng J, Shen B, Lv M, Li Y. Anti-HER3 Monoclonal Antibody Inhibits Acquired Trastuzumab-Resistant Gynecologic Cancers. Technology in cancer research \& treatment. 2015. 
31. Mohd Nafi SN, Generali D, Kramer-Marek G, Gijsen M, Strina C, Cappelletti M, Andreis D, Haider S, Li JL, Bridges E, Capala J, Ioannis R, Harris AL, et al. Nuclear HER4 mediates acquired resistance to trastuzumab and is associated with poor outcome in HER2 positive breast cancer. Oncotarget. 2014; 5: 5934-5949. doi: 10.18632/oncotarget.1904.

32. White CD, Brown MD, Sacks DB. IQGAPs in cancer: a family of scaffold proteins underlying tumorigenesis. FEBS letters. 2009; 583: 1817-1824.

33. Patel V, Hood BL, Molinolo AA, Lee NH, Conrads TP, Braisted JC, Krizman DB, Veenstra TD, Gutkind JS. Proteomic analysis of laser-captured paraffinembedded tissues: a molecular portrait of head and neck cancer progression. Clinical cancer research. 2008; 14: 1002-1014.

34. White CD, Khurana H, Gnatenko DV, Li Z, Odze RD, Sacks DB, Schmidt VA. IQGAP1 and IQGAP2 are reciprocally altered in hepatocellular carcinoma. BMC gastroenterology. 2010; 10: 125-230X-10-125.

35. Zhou R, Skalli O. Identification of cadherin-11 downregulation as a common response of astrocytoma cells to transforming growth factor-alpha. Differentiation; research in biological diversity. 2000; 66: 165-172.

36. Walch A, Seidl S, Hermannstadter C, Rauser S, Deplazes J, Langer R, von Weyhern CH, Sarbia M, Busch R, Feith M, Gillen S, Hofler H, Luber B. Combined analysis of Rac1, IQGAP1, Tiam1 and E-cadherin expression in gastric cancer. Modern pathology. 2008; 21: 544-552.

37. White CD, Li Z, Dillon DA, Sacks DB. IQGAP1 protein binds human epidermal growth factor receptor 2 (HER2) and modulates trastuzumab resistance. The Journal of biological chemistry. 2011; 286: 29734-29747.

38. Kim JW, Im SA, Kim M, Cha Y, Lee KH, Keam B, Kim MA, Han SW, Oh DY, Kim TY, Kim WH, Bang YJ. The prognostic significance of HER2 positivity for advanced gastric cancer patients undergoing first-line modified FOLFOX-6 regimen. Anticancer Research. 2012; 32: 1547-1553.

39. Bayrak M, Olmez OF, Kurt E, Cubukcu E, Evrensel T, Kanat O, Manavoglu O. Prognostic significance of c-erbB2 overexpression in patients with metastatic gastric cancer. Clinical \& translational oncology. 2013; 15: 307-312.

40. He XX, Ding L, Lin Y, Shu M, Wen JM, Xue L. Protein expression of HER2, 3, 4 in gastric cancer: correlation with clinical features and survival. Journal of clinical pathology. 2015.

41. Normanno N, Bianco C, Strizzi L, Mancino M, Maiello MR, De Luca A, Caponigro F, Salomon DS. The ErbB receptors and their ligands in cancer: an overview. Current Drug Targets. 2005; 6: 243-257.

42. Zuo Q, Liu J, Zhang J, Wu M, Guo L, Liao W. Development of trastuzumab-resistant human gastric carcinoma cell lines and mechanisms of drug resistance. Scientific reports. 2015; 5: 11634.

43. Sliwkowski MX, Lofgren JA, Lewis GD, Hotaling TE, Fendly BM, Fox JA. Nonclinical studies addressing the mechanism of action of trastuzumab (Herceptin). Seminars in oncology. 1999; 26: 60-70.

44. Lane HA, Beuvink I, Motoyama AB, Daly JM, Neve RM, Hynes NE. ErbB2 potentiates breast tumor proliferation through modulation of $\mathrm{p} 27$ (Kip1)-Cdk2 complex formation: receptor overexpression does not determine growth dependency. Molecular and cellular biology. 2000; 20: 3210-3223.

45. Neve RM, Sutterluty H, Pullen N, Lane HA, Daly JM, Krek W, Hynes NE. Effects of oncogenic ErbB2 on G1 cell cycle regulators in breast tumour cells. Oncogene. 2000; 19: 1647-1656.

46. Baselga J, Albanell J, Molina MA, Arribas J. Mechanism of action of trastuzumab and scientific update. Seminars in oncology. 2001; 28: 4-11.

47. Ma J, Lyu H, Huang J, Liu B. Targeting of erbB3 receptor to overcome resistance in cancer treatment. Molecular cancer. 2014; 13: 105-4598-13-105.

48. Kruser TJ, Wheeler DL. Mechanisms of resistance to HER family targeting antibodies. Experimental cell research. 2010; 316: 1083-1100.

49. Canfield K, Li J, Wilkins OM, Morrison MM, Ung M, Wells W, Williams CR, Liby KT, Vullhorst D, Buonanno A, Hu H, Schiff R, Cook RS, et al. Receptor tyrosine kinase ERBB4 mediates acquired resistance to ERBB2 inhibitors in breast cancer cells. Cell cycle (Georgetown, Tex.). 2015; 14: 648-655.

50. Kornev AP, Haste NM, Taylor SS, Eyck LF. Surface comparison of active and inactive protein kinases identifies a conserved activation mechanism. Proceedings of the National Academy of Sciences of the United States of America. 2006; 103: 17783-17788.

51. Kornev AP, Taylor SS, Ten Eyck LF. A helix scaffold for the assembly of active protein kinases. Proceedings of the National Academy of Sciences of the United States of America. 2008; 105: 14377-14382.

52. Qiu C, Tarrant MK, Choi SH, Sathyamurthy A, Bose R, Banjade S, Pal A, Bornmann WG, Lemmon MA, Cole PA, Leahy DJ. Mechanism of activation and inhibition of the HER4/ErbB4 kinase. Structure (London, England: 1993). 2008; 16: 460-467.

53. Adams JA. Activation loop phosphorylation and catalysis in protein kinases: is there functional evidence for the autoinhibitor model?. Biochemistry. 2003; 42: 601-607.

54. Lew J. MAP kinases and CDKs: kinetic basis for catalytic activation. Biochemistry. 2003; 42: 849-856.

55. Bertoni L, Zoli W, Mucciolo E, Ricotti L, Nergadze S, Amadori D, Giulotto E. Different genome organization in 
two new cell lines established from human gastric carcinoma. Cancer genetics and cytogenetics. 1998; 105: 152-159.

56. Zoli W, Ricotti L, Lenzi L, Roncuzzi L, Zini N, Amadori D, Gruppioni R, Sensi A, Gasperi-Campani A. Molecular genetics and in vitro sensitivity of a new human cell line, KKP, from a gastric adenocarcinoma. Cancer genetics and cytogenetics. 1998; 105: 43-49.

57. Leonard CE, Chan DC, Chou TC, Kumar R, Bunn PA. Paclitaxel enhances in vitro radiosensitivity of squamous carcinoma cell lines of the head and neck. Cancer research. 1996; 56: 5198-5204.

58. Pignatta S, Arienti C, Zoli W, Di Donato M, Castoria G, Gabucci E, Casadio V, Falconi M, De Giorgi U, Silvestrini R, Tesei A. Prolonged exposure to (R)-bicalutamide generates a LNCaP subclone with alteration of mitochondrial genome. Molecular and cellular endocrinology. 2014; 382: 314-324.

59. Arienti C, Tesei A, Carloni S, Ulivi P, Romeo A, Ghigi G, Menghi E, Sarnelli A, Parisi E, Silvestrini R, Zoli W. SLUG silencing increases radiosensitivity of melanoma cells in vitro. Cellular oncology (Dordrecht). 2013; 36: 131-139.

60. Li H, Durbin R. Fast and accurate short read alignment with Burrows-Wheeler transform. Bioinformatics (Oxford, England). 2009; 25: 1754-1760.

61. McKenna A, Hanna M, Banks E, Sivachenko A, Cibulskis K, Kernytsky A, Garimella K, Altshuler D, Gabriel S, Daly M, DePristo MA. The Genome Analysis Toolkit: a MapReduce framework for analyzing next-generation DNA sequencing data. Genome research. 2010; 20: 1297-1303.

62. Cibulskis K, Lawrence MS, Carter SL, Sivachenko A, Jaffe D, Sougnez C, Gabriel S, Meyerson M, Lander ES, Getz G. Sensitive detection of somatic point mutations in impure and heterogeneous cancer samples. Nature biotechnology. 2013; 31: 213-219.

63. Wang K, Li M, Hakonarson H. ANNOVAR: functional annotation of genetic variants from high-throughput sequencing data. Nucleic acids research. 2010; 38: e164. 